\title{
SCRUM AGILE FRAMEWORK IN E-BUSINESS PROJECT MANAGEMENT: AN APPROACH TO TEACHING SCRUM
}

\author{
Jelena Mihajlović Milićević, Filip Filipović, Ivan Jezdović, \\ Tamara Naumović, Miloš Radenković \\ Faculty of Organisational Sciences, University of Belgrade, Serbia
}

\begin{abstract}
With the rise of agile within companies worldwide, it is crucial for information systems education to keep up with this trend to ensure curriculum and courses are up-to-date. The topic of agile in teaching and learning is critically important. This paper attempts to point out the need to understand and implement learning about the agile approach to education. The aim of the paper is to explain Scrum and its application in student education in IT project management areas. We propose a method for managing students' project using Scrum, which enables students to learn the subject matter in a project-oriented approach. The idea is that students who study IT project management learn Scrum by leading another student team making an IoT project. The implementation was provided at The Department of e-business, Faculty of Organisational Sciences. In conclusion, the results of teaching Scrum in this way are presented and show that scrum application has a positive impact on project implementation and student education.
\end{abstract}

Key words: Scrum agile framework, project management, agile methods, agile in education.

\section{INTRODUCTION}

Building innovative business models, processes and products require a new approach to management in general, and project management in particular (Highsmith, 2009). Project management needs to move faster, become more flexible and responsive to customers. Agile methodologies aim at fulfilling this role (Berbegal-Mirabent, GilDoménech, \& Berbegal-Mirabent, 2017).

Agile software development methodologies have changed the way many software developers organize their work and projects, for example as in Scrum by delegating responsibilities, empowering individuals and delaying decisions. The main driver in most methods is "accelerated delivery" realized by focusing on small steps, incremental development, prototyping and quick feedback rather than extensive planning and documentation (Boehm, 2002). Agile should carry less risk than the traditional "waterfall" approach. It should help the project team in their joint work to do the job in the best way. Keys to success are contained in a communication, team dedication, strong leadership, and good planning (Milenkovic, 2018).

Implementation of agile methods significantly alleviates organizations to develop software for customized services and products in ebusiness. By using agile methods, organizations gain a competitive edge and the ability to adapt to current market trends. Furthermore, in this way, organizations can even improve their flexibility (MihajlovicMilicevic, Bogdanovic, \& Despotovic-Zrakic, 2018).

In parallel with the development of agile methodologies, there is a constant challenge of learning agile methodologies. For centuries, educators have been searching for ideal teaching approaches. For more than 20 years, we have been observing a strong shift from traditional teaching methods where the focus is on the content fed to a learner to learnercentered approaches focusing on the "needs, skills, and interests of the learner" (Norman, \& Spohrer, 1996, p. 26). This shift has been supported and facilitated by rapid development and adaptation of educational technologies. Technological advances fostered the creation

Corresponding author. Email: jelenamm@elab.fon.bg.ac.rs

ISSN 2560-4961 (online)

(C) 2019 IPMA Serbia

doi: 10.18485/epmj.2019.9.1.7 
of engaging learning environments that support individual learning styles, self-paced learning, and interactivity that significantly complement if not replace "traditional" teaching (Hannafin, \& Land, 1997). One approach that has been successful is active learning. Active learning can engage students in the process of thoroughly learning a topic leading many educators to urge increased use of this approach (Bonwell, \& Eison, 1991). Furthermore, active learning exercises can engage students in higher-order thinking tasks such as analysis, synthesis, and evaluation (Bonwell, \& Eison, 1991) which may help when approaching concepts that students may have little exposure to outside the classroom.

Agile learning is a way of active learning. It applies the processes and principles of agile software development to the context of learning. Agile learning stands in contrast to traditional project-based learning, which is often characterized by a linear process through which students develop deliverables (Lee, Huh, \& Reigeluth, 2015; Melles, Anderson, Barrett, \& Thompson-Whiteside, 2015).

Agile methodologies are particularly important for education in IT areas. As the IT industry develops at a high speed, and the invention quickly becomes accepted and originate as innovation, it would be a good idea to find a way to run this tempo through the education system. This means that it is necessary to introduce equivalent innovations in teaching in order to enable students to learn what they will need in practice (Radenkovic, DespotovicZrakic, Bogdanovic, Barac, \& Labus, 2017).

Therefore, the aim of this paper is to propose in the academic world, and more specifically, at technical university, an alternative methodology for group work (Scrum) in which students can learn to self-manage their time and resources for meaningful active learning. The context for this study is Scrum project management (Schwaber, \& Beedle, 2002). However, the challenge with teaching Scrum, especially to undergraduates, is that many students' have no prior work-related experience and may have a difficult time understanding the topic. Thus, this study aims to explore how different approaches to teaching Scrum (i.e. active learning) may increase a students' perception of learning.

In order to understand how it can be effectively applied in the classroom, the Scrum framework will be explained in detail.

\section{SCRUM}

One of the popular agile approaches to software development is Scrum. Scrum is a framework for developing, delivering, and sustaining complex products. It is a framework within which people can address complex adaptive problems, while productively and creatively delivering products of the highest possible value. It is characterized by short project cycles, called "sprints" in which a usable deliverable is fully planned, designed, built, tested, reviewed, and launched (Schwaber, \& Sutherland, 2017). Scrum is:

- Lightweight

- Simple to understand

- Difficult to master

The Scrum framework consists of Scrum Teams and their associated roles, events, artifacts, and rules. Each component within the framework serves a specific purpose and is essential to Scrum's success and usage. The essence of Scrum is a small team of people, highly flexible and adaptive. Scrum Teams deliver products iteratively and incrementally, maximizing opportunities for feedback. The Scrum Team consists of a Product Owner, the Development Team, and a Scrum Master. Scrum Teams are self-organizing and crossfunctional. 


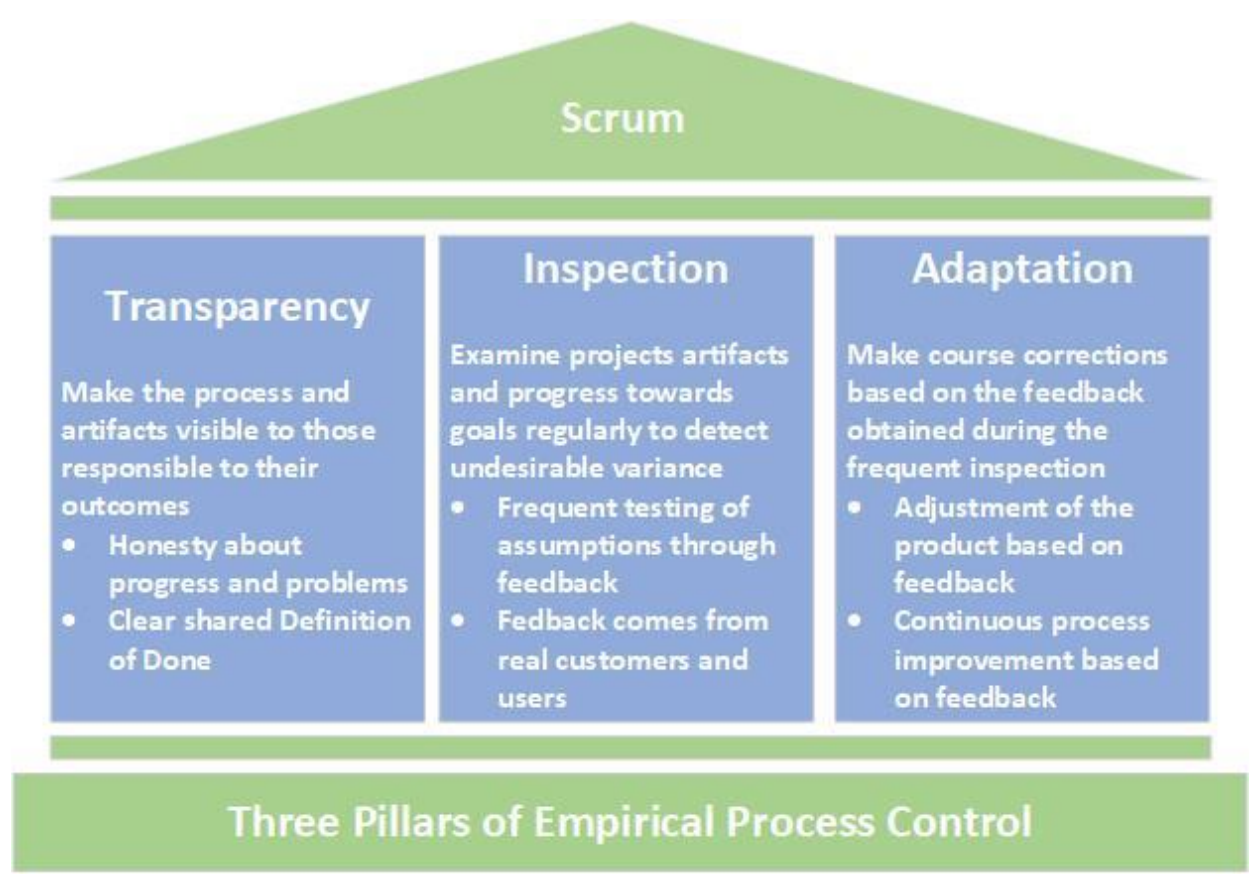

Figure 1: Three Pillars of Empirical Process Control

Scrum is founded on empirical process control theory or empiricism. Empiricism asserts that knowledge comes from experience and making decisions based on what is known. Three pillars showed in Figure 1. uphold every implementation of empirical process control: transparency, inspection, and adaptation.

The heart of Scrum is a Sprint (Figure 2), a time-box of one month or less during which a "Done", useable, and potentially releasable product Increment is created. Sprints are limited to one calendar month. A new Sprint starts immediately after the conclusion of the previous Sprint. Sprints contain and consist of the:

- Sprint Planning,

- Daily Scrums,

- The development work,

- The Sprint Review and

- The Sprint Retrospective.

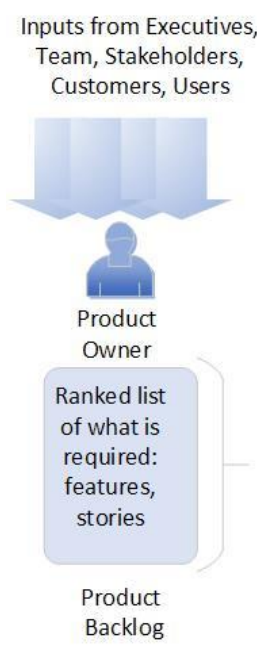

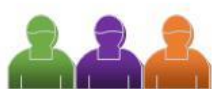

The Team

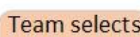
starting at top as much as it can commit to deliver by end of Sprint

Sprint Planning Meeting

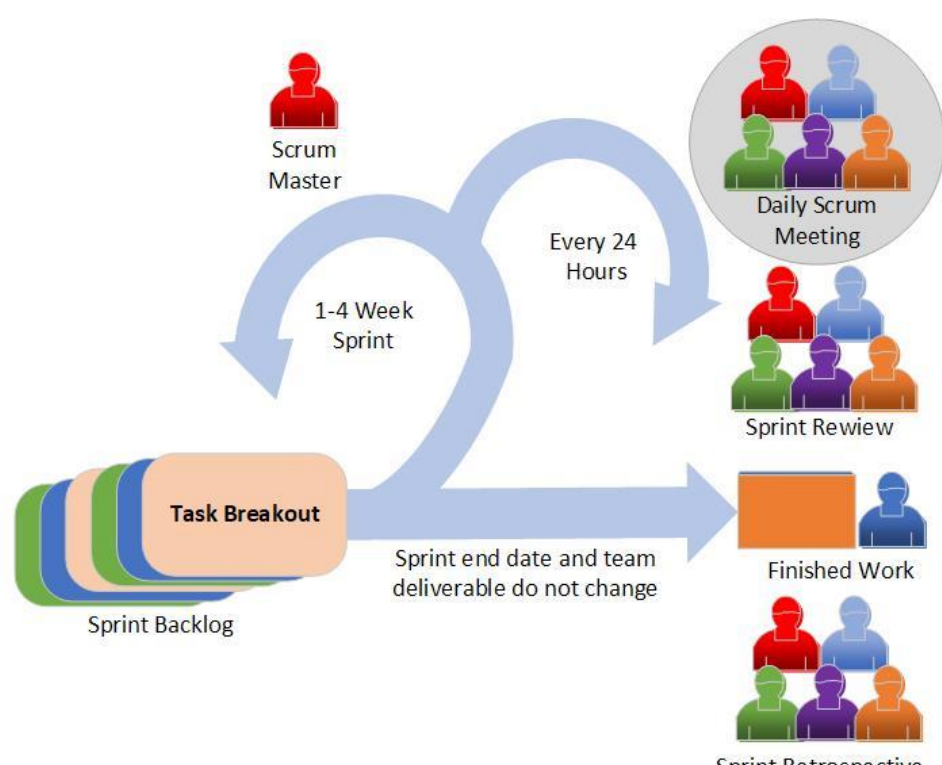

Figure 2: Sprint Process 


\subsection{Scrum artifacts}

Scrum's artifacts represent work or value to provide transparency and opportunities for inspection and adaptation. Those are:

- The Product Backlog is an ordered list of everything that is known to be needed in the product. The Product Owner is responsible for the Product Backlog.

- The Sprint Backlog is the set of Product Backlog items selected for the Sprint, plus a plan for delivering the product Increment and realizing the Sprint Goal.

- The Increment is the sum of all the Product Backlog items completed during a Sprint and the value of the increments of all previous Sprints.

\subsection{Scrum in education}

How is the process of the Scrum framework briefly explained in the previous section, in this section will explain how it is most commonly used in teaching because one of the most interesting applications of the Scrum methodology outside the field of information technology development is in the field of education and learning. The Scrum approach, if applied to an educational setting, could foster self-regulated learning, especially if supported by an appropriate learning environment. For example, the Dutch University Ashram College uses Scrum named eduScrum. They incorporated Scrum as a way of learning to make their students more efficient. Using eduScrum, they succeeded in developing more efficient work in the team (Todorovic, ToljagaNikolic, \& Bjelica, 2018). Like this example, in the last couple of years, many faculties, which are mostly technically oriented, have introduced courses that explain and teach the application of the Scrum framework in education. According to the State of Agile Survey, Scrum and its variants (Scrum/XP Hybrid and Scrumban) are used by $72 \%$ of respondents ("9th Annual State of Agile Development Survey", 2015). Therefore, there is an increasing need to acquaint students' with this topic and many educators are faced with the issue of how to incorporate Scrum into their software engineering courses.

Viljan Mahnic has done a thorough analysis of the approaches and ways of implementing the Scrum framework in education and describes a course designed to teach Scrum and project planning to undergraduate students'. He came to the following results, exploring an outline of the literature describing hitherto experienced in teaching Scrum.

Table 1: Classification of studies by topic (Mahnic, 2015)

\begin{tabular}{|c|l|c|}
\hline Group & \multicolumn{1}{|c|}{ Topic } & Number of Studies \\
\hline 1 & Teaching Scrum through practical work on student projects & 7 \\
\hline 2 & Teaching Scrum through educational games & 4 \\
\hline 3 & Students' perceptions of Scrum practices and teamwork & 3 \\
\hline 4 & Pedagogical issues & 1 \\
\hline 5 & General experience and recommendations & 2 \\
\cline { 2 - 3 } & Teaching aids & 2 \\
\cline { 2 - 3 } & Scrum and other process models & \multicolumn{2}{|c|}{} \\
\hline
\end{tabular}

For the purpose of his research, the studies were classified by their main topic into five groups as shown in Table 2 . The table clearly indicates that the most widespread approach to teaching Scrum is through practical work on student projects. This approach takes into account the statement of Scrum creators that Scrum is simple to understand yet difficult to master (Reichlmayr, 2011). Courses of this type mainly exploit the benefits of capstone projects that simulate professional working environment as much as possible. Apart from seven studies in group 1 that concentrate on the content of such courses (i.e. studies by Damian, Lassenius, Paasivaara, Borici, and Schroter (2012); Kropp, and Meier (2013); Mahnic (2012); Paasivaara, M., Heikkila, V., Lassenius, C., and Toivola (2014); Reichlmayr (2011); Scharf, and Koch (2013), and Zorzo, De Ponte, and Lucredio (2013)), student projects also served as a basis for most of studies dealing with other topics, e.g. students' perceptions of Scrum practices and teamwork (studies by Mahnic (2010), Mahnic, and Hovelja (2014), Mahnic, and Rozanc (2012) and Pozenel (2013)) and pedagogical issues 
(studies by Gamble, and Hale (2013), Igaki, Fukuyasu, Saiki, Matsumoto, and Kusumoto (2014) and Scott, Rodriguez, Soria, and Campo (2014)). (Mahnic, 2015)

Although there are studies focusing on the teaching of agile methodologies (e.g. Devedzic, \& Milenkovic (2011); Lu, \& Declue, 2011)), "the literature on teaching agile project management is just starting to emerge" (Cubric, 2013, p.121). Despite the growth in the application of agile methodologies in the industry, academic research on this topic is still scarce, as most of the existing publications are written by practitioners or consultants (Abrahamsson, Warsta, Siponen, \& Ronkainen (2003); Chow, \& Cao (2008); Conboy (2009)). A need for more empirical studies is thus obvious. In the specific context of agile project management, learning experiences are underrepresented compared to the use of agile methodologies in software-related disciplines. In spite of the fact that in recent years this trend seems to start reverting (Cubric, 2013), there is still a long way to go.

\section{SCRUM IMPLEMENTATION - PROJECT MANAGEMENT DEVELOPMENT IOT}

\subsection{Procedure}

The Department of e-business, Faculty of Organizational Sciences is a leader in educational and scientific works in the fields of the electronic and mobile business, Internet technologies, computer simulations and IT project management. These well thought out and conducted courses should contribute to better study conditions, better student results, greater interest among students and the competitive advantage of the Faculty of Organizational Sciences in relation to other faculties. ("Center for the Internet of things", 2019).

The implementation of the Scrum framework in the educational environment is provided through an example of the realization of the IoT projects at The Department of e-business.

The idea was to find the most suitable solution for organizing the IoT projects with the help of well-designed project management, using the Scrum framework and adapting it to the needs of the educational environment. The IoT course and the Risk management in e-business course in according to the agile framework Scrum, in order to enable students to master the essence of agile access through practical work. Students who study Risk management in ebusiness were tasked with leading an IoT project. They learned Scrum by leading student teams that realize IoT projects in IoT course and they were assigned the role of Scrum Master. The IoT team performed the project, with the supervision of the student Scrum Master, and at the same time, working in the Scrum framework, they gain experience that they will later use in professional work. The professors controlled and evaluated projects.

\subsection{Example of the realized project}

A suggested way of teaching has been implemented and it will be explained through an example of the project management of the IoT System for a restaurant using the Raspberry Pi computer for automatization of serving guests (Figure 3.). 


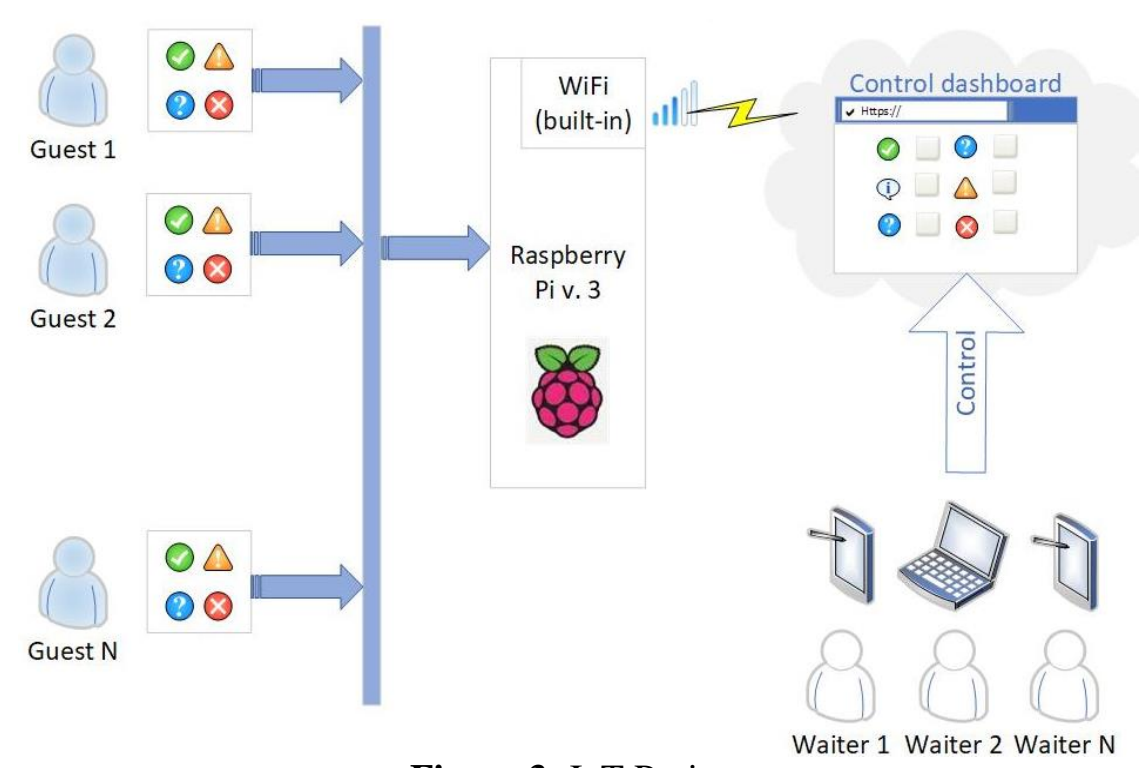

Figure 3: IoT Project

A guest will use a keyboard with four buttons to send information to a waiter regarding calling waiters, canceling the order and registering a type of payment. The input will be processed by Raspberry PI computer which will send information to the cloud. Waiters will receive requests accessing the portal.

IT project management was based on the use of the Scrum framework:

The Product Owner (Professor) created a list of product features called a Product Backlog. The next step was the Sprint Planning. Members of the Team and a Scrum Master were selected. Along the way, the Scrum Master (team facilitator but also a team member) keeps the team focused on its goal and generally facilitates the group and tries to fix any problems or issues. During Sprint Planning, the Team (learners in a group) and Scrum Master plus the product owner if necessary break down the features from the backlog into tasks and decided what they can complete in the sprint (time available, given the resources to hand) and make a Sprint Backlog (list of tasks).The Team had a certain amount of time, the Sprint - to complete its work. They met daily to assess its progress with a daily Scrum or 'stand up' meeting. Team members stood up and spoke what they have achieved, what they are going to do next and discuss any issues, challenges and help needed (Royale, \& Nikolic, 2016). All segments of the Sprint were monitored with the help of the OpenProject software.

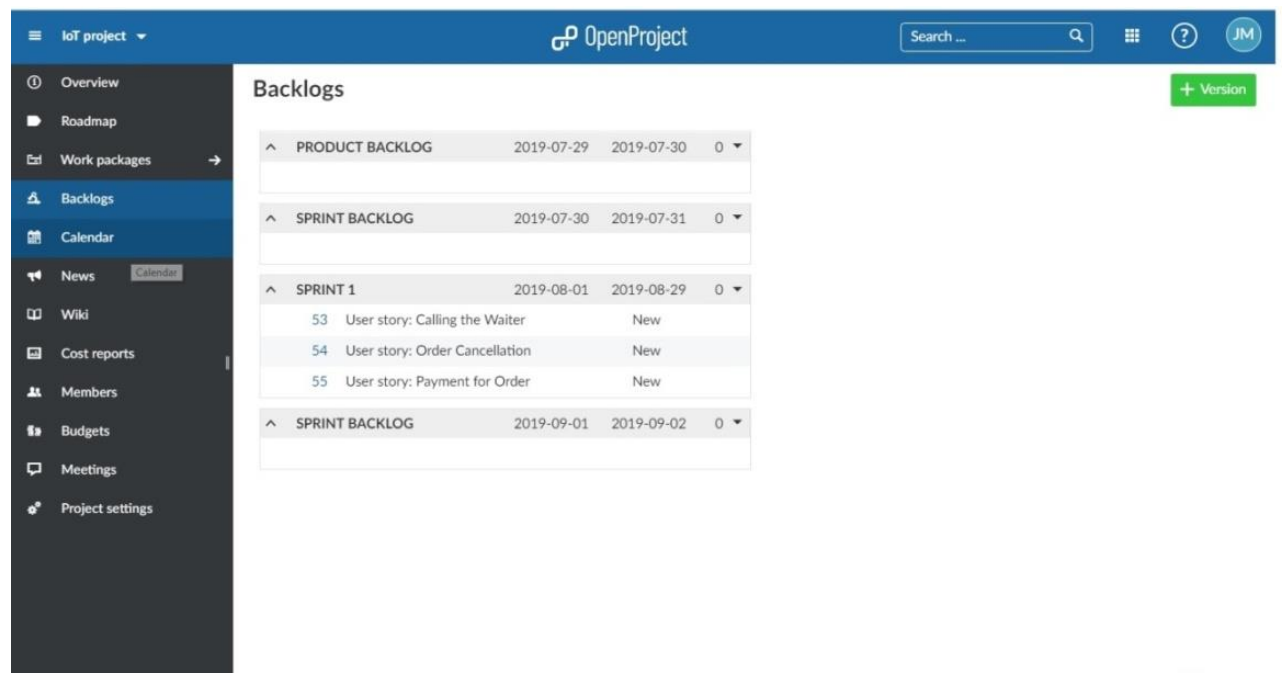

Figure 4: OpenProject - Project Overview 


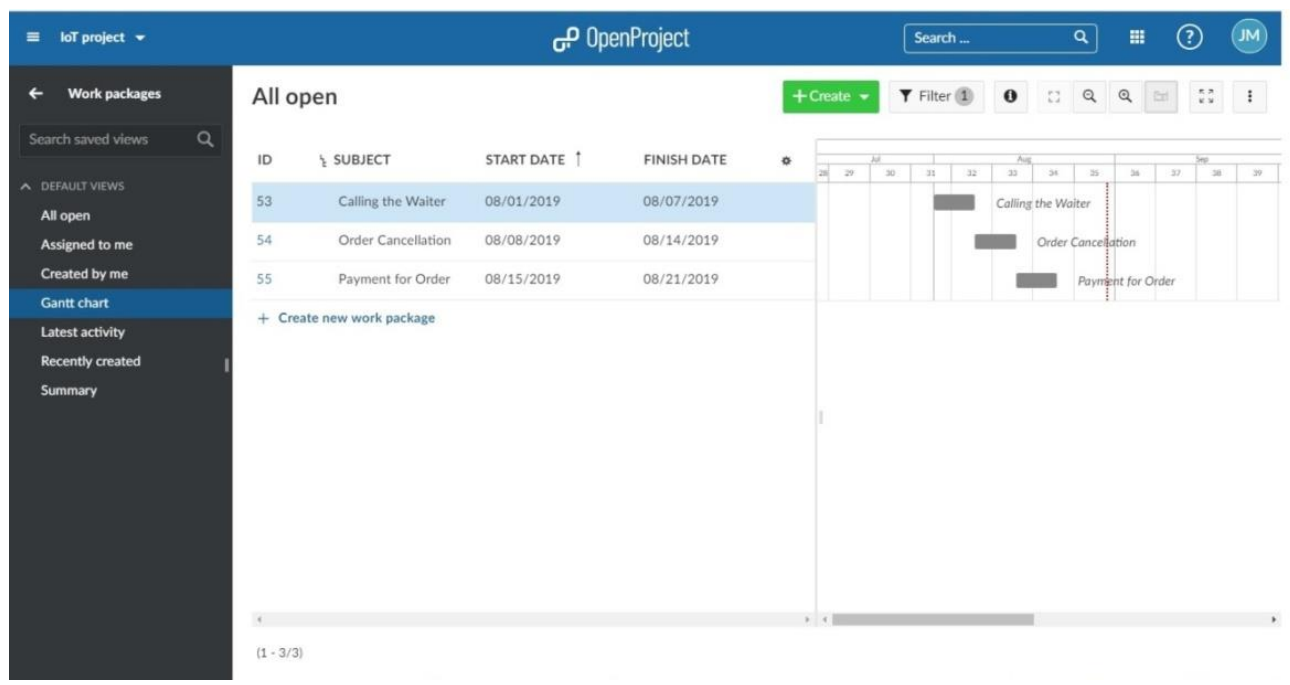

Figure 5: OpenProject - Gantt chart

At the end of the Sprint, the first version of the product was ready to use. The Sprint ended with a Sprint Review in which the Team and Product Owner inspect what they have done so far and think about what needs still to be done. At this stage, the team showed the Product Owner user stories that were done. This was the point where the Product Owner accepted a solution. Also, it could reject the work if it doesn't meet the criteria agreed.

\section{DISCUSSION}

The project of IoT System for a restaurant was successfully implemented using the Scrum framework but with some exceptions and limitations which have not had a significant influence on obtained results. For example, a Sprint Retrospective may be used to look at how the team worked together and if any improvements can be made, but it was not held on this project. Feedback from students' confirmed a positive attitude towards learning agile methodologies through practical project work. It becomes evident that students' were enthusiastic about the practical approach used in the activity. Students realized that problems were more efficiently resolved with good communication, but they were confronted with difficulties in accepting the opposite meanings. They think that good interaction with professors was helpful. Professors motivated them and directed them properly. Most students like how roles and responsibilities were split. The Scrum Master's role was the most demanding, and it was not easy to understand it. Also, monitoring of the project using the Open Project software is partially mastered. It was most difficult to maintain the daily discipline in completing the required reports on what has been done and at the same time monitoring the work of colleagues from the team. In the end, the students liked to teach in this way. For them, this educational approach can be useful for preparing a final exam in the course and a good exercise for work in real working conditions.

\section{CONCLUSION}

Before starting a professional life, human resources are formed at universities. Changes, speed, scalability, innovation, lifelong learning - all of these qualities in the $21^{\text {st }}$ century have become imperative. The question that arises is how to operate in such an environment? In addition, how to design young intellectuals to manage in turbulent and for sure challenging circumstances? Not all students' can self-learn in public spaces or become coders or entrepreneurs, and mass schooling will not disappear in a digital whirlwind of change overnight. The agile learning methodology is a potential answer to transforming schooling from within by keeping structure but releasing agency and control within it by providing participant practice identities within a project (Royale, \& Nikolic, 2016).

These are the reasons why the education of young professionals should introduce learning about agile approaches. Moreover, the introduction of education on agile methodologies and their application is necessary, because it is an environment in 
which it will work (Mihajlovic-Milicevic et al., 2018).

The next step in this research will be to organize, monitor, control and evaluate a large number of projects using two frameworks: $\mathrm{SAFe}$ and Scrum. The idea is that all projects in courses will be organized in accordance with the Scrum agile framework, in order to equip students with the essence of an agile approach through hands-on work. The organization of projects on the course will be conceived with the help of SAFe so that professors can supervise the work of students, without increasing the teaching staff.

\section{REFERENCES}

Abrahamsson, P., Warsta, J., Siponen, M. T., \& Ronkainen, J. (2003). New directions on agile methods: A comparative analysis. In Proceedings of the 25th International Conference on Software Engineering (ICSE'03), IEEE Press, 244-254.

Berbegal-Mirabent, J., Gil-Domenech, D., \& Berbegal-Mirabent, N. (2017). Teaching agile methodologies in a project management course. 3rd International Conference on Higher Education Advances

Boehm, B. (2002). Get ready for agile methods, with care. Computer, 35, 64-69.

Bonwell, C. C., \& Eison, J. A. (1991). Active Learning: Creating Excitement in the Classroom. 1991 ASHE-ERIC Higher Education Reports. ERIC.

Center for Internet of things. (2019). Retrieved from https://en.elab.fon.bg.ac.rs/centerinternet-things

Chow, T., \& Cao, D.-B. (2008). A survey study of critical success factors in agile software projects. Journal of Systems and Software, 81(6), 961-971.

Conboy, K. (2009). Agility from first principles: Reconstructing the concept of agility in information systems development. Information Systems Research, 20(3), 329-354.

Cubric, M. (2013). An agile method for teaching agile in business schools. International Journal of Management Education, 11(3), 119-131.

Damian, D., Lassenius, C., Paasivaara, M., Borici, A., \& Schroter, A. (2012).
Teaching a globally distributed project course using Scrum practices. Proc. 2nd Inter. Workshop on Collaborative Teaching of Globally Distributed Software Develop. CTGDSD 2012, Zurich, Switzerland, 30-34.

Devedzic, V., \& Milenkovic, S. R. (2011). Teaching agile software development: a case study. IEEE Transactions on Education, 54(2), 273-278.

Gamble, R. F., \& Hale, M. L. (2013). Assessing individual performance in agile undergraduate software engineering teams. Proc. 2013 Frontiers in Educ. Conf., Oklahoma City, USA, 1678-1684.

Hannafin, M. J., \& Land, S. M. (1997). The Foundations and Assumptions of Technology-Enhanced Student-Centered Learning Environments. Instructional Science, 25(3), 167-202.

Highsmith, J. (2009). Agile project management: creating innovative products. Pearson Education.

Igaki, H., Fukuyasu, N., Saiki, S., Matsumoto, S., \& Kusumoto, S. (2014). Quantitative assessment with using ticket driven development for teaching Scrum framework. Proceedings of the $36^{\text {th }}$ International Conference on Software Engineering, Hyderabad, Hyderabad, India, 372-381.

Kropp, M., \& Meier, A. (2013). Teaching agile software development at university level: values, management, and craftsmanship. Proc.26th Conf. on Software Engng. Educ. and Training, San Francisco, USA, 179-188.

Lee, D., Huh, Y., \& Reigeluth, C. (2015). Collaboration, Intragroup Conflict, and Social Skills in Project-Based Learning, Instructional Science, 43(5), 561-590.

Lu, B., \& DeClue, T. (2011). Teaching agile methodology in a software engineering capstone course. Journal of Computing Sciences in Colleges, 26(5), 293-299.

Melles, G., Anderson, N., Barrett, T., \& Thompson-Whiteside, S. (2015). Problem Finding through Design Thinking in Education. In Patrick Blessinger, John M. Carfora (Eds.), Inquiry-Based Learning for Multidisciplinary Programs: A Conceptual and Practical Resource for Educators (Innovations in Higher Education Teaching and Learning, 
Volume 3), Bingley, UK: Emerald, 191209.

Mahnic, V. (2010). Teaching Scrum through team-project work: students' perceptions and teacher's observations. International Journal of Engineering Education, 26(1), 96-110.

Mahnic, V. (2012). A capstone course on agile software development using Scrum. IEEE Transactions on Education, 55(1), 99106.

Mahnic, V. (2015). Scrum in software engineering courses: an outline of the literature. IEEE Transactions on Education, 55(1), 99-106.

Mahnic, V., \& Hovelja, T. (2014). Teaching user stories within the scope of a software engineering capstone course: analysis of students' opinions. International Journal of Engineering Education, 30(4), 901915.

Mahnic, V., \& Rozanc, I. (2012). Students' perceptions of Scrum practices. MIPRO 2012 - Proceedings of the 35th International Convention of Information, Communication, Technology, Electronics and Microelectronics, Opatija, Croatia, 1178-1183.

Mihajlovic-Milicevic, J., Bogdanovic, Z., \& Despotovic-Zrakic, M. (2018). SAFe Agile Framework in Project Management, Symorg 2018.

Milenkovic, M. (2018). Model za uvođenje inovacija u portfolio kompanije zasnovan na projektnom upravljanju, doktorska disertacija, Univerzitet u Novom Sadu, Fakultet tehnickih nauka. Retrieved from http://www.ftn.uns.ac.rs/n1031129270/di sertacija

Norman, D. A., \& Spohrer, J. C. (1996). Learner-Centered Education. Communications of the ACM, 39(4), 2427.

Paasivaara, M., Heikkila, V., Lassenius, C., \& Toivola, T. (2014) Teaching students Scrum using LEGO blocks. Proceedings of the $36^{\text {th }}$ International Conference on Software Engineering, Hyderabad, India, 382-391.

Pozenel, M. (2013). Assessing teamwork in a software engineering capstone course.
World Transactions on Engineering and Technology Education, 11(1), 6-12.

Radenkovic, B., Despotovic-Zrakic, M., Bogdanovic, Z., Barac, D., \& Labus, A. (2017), IT Education as an Opportunity for Uprising of Serbian Economy, Management: Journal of Sustainable Business and Management Solutions in Emerging Economies

Reichlmayr, T. (2011). Working towards the student Scrum - developing agile Android applications. Proceedings of the 118th ASEE Annual Conference and Exposition, Vancouver, Canada

Royale, K., \& Nikolic, J. (2016). A modern mixture, Agency, Capability, Technology and 'Scrum': Agile Work Practices for Learning and Teaching in Schools, Journal of Education \& Social Policy, 3(3).

Scharf, A., \& Koch, A. (2013). Scrum in a software engineering course: an in-depth praxis report. Proceedings of the $26^{\text {th }}$ International Conference on Software Engineering Education and Training, San Francisco, USA, 159-168.

Scott, E., Rodríguez, G., Soria, Á., \& Campo, M. (2014). Are learning styles useful indicators to discover how students use Scrum for the first time? Computers in Human Behavior, 36, 56-64.

Schwaber, K., \& Beedle, M. (2002). Agile software development with Scrum, Volume 1. Prentice Hall Upper Saddle River.

Schwaber, K., \& Sutherland, J. (2017). The Definitive Guide to Scrum: The Rules of the Game

Todorovic, M., Toljaga-Nikolic, D., \& Bjelica, D. (2018). People-Oriented Principles and Values of Agile Project Management European Project Management Journal, 8(2), 3-8.

VersionOne, 9th Annual State of Agile Development Survey. (2015). http://info.versionone. com/state-of-agiledevelopment-survey-ninth.html

Zorzo, S. D., De Ponte, L., \& Lucredio, D. (2013). Using scrum to teach software engineering: a case study. Proceedings 2013 Frontiers in Education Conference, Oklahoma City, USA, 455-461. 